\title{
Steps Taken and the Steps that Lie Ahead: The Current State of Our Accreditation Journey
}

\author{
Jung A Kim ${ }^{1}$, Hyejung Chang ${ }^{2}$ \\ ${ }^{1}$ Associate Editor of Business Communication Research and Practice, Hanyang University, Seoul, Korea \\ ${ }^{2}$ Editor of Business Communication Research and Practice, Kyung Hee University, Seoul, Korea
}

The official journal of an academic society is a collection of its academic accomplishments and thus offers a reflection of the society's academic identity, quality, and role within its discipline (Chang \& Kim, 2018). Starting from the publication of its first issue of Business Communication Research and Practice (BCRP) in 2018, the Korean Association for Business Communication (KABC) has proudly refined and conveyed its academic identity within Korea and beyond by proving itself to be a source of knowledge that can be applied in the theoretical, educational, and practical spheres of business communication.

Since its inception, $B C R P$ has prided itself in its commitment to four objectives (Chang \& Kim, 2018). First, as implied in its title, in addition to the theoretical and academic domains of business communication, the scope of $B C R P$ encompasses that of practice, where theories and academic concepts are applied, research problems are proposed, and research is conducted. The KABC has always sought to bridge the divide between academia and practice, and this journal is an extension of this aim. Second, although the journal is published in Korea, every issue has been published in the English language. The decision to do so was based on the desire of the KABC to provide an

Received: Jun 2, 2021 Revised: Jul 14, 2021 Accepted: Jul 19, 2021 Corresponding author: Hyejung Chang

School of Management, Kyung Hee University, 26 Kyungheedae-ro, Dongdaemun-gu, Seoul 02447, Korea

Tel: +82-2-961-9432, Fax: +82--2-961-0515, E-mail: hjchang@khu.ac.kr

This is an Open Access article distributed under the terms of the Creative Commons Attribution Non-Commercial License (http://creativecommons.org/licenses/ by-nc/4.0/) which permits unrestricted non-commercial use, distribution, and reproduction in any medium, provided the original work is properly cited.

Copyright (๑) 2021 Korean Association for Business Communication. intellectual forum within which Western and Eastern scholars and practitioners could share insights that are both culturally distinct and universally relevant. Third, $B C R P$ is published as an open-access journal under a Creative Commons license in order to give readers around the world the opportunity to read and cite articles from the journal and interact with the insights they encounter here in their own work. With its aim of reaching practitioners in a diversity of fields, providing open access to knowledge was key. Fourth, the $B C R P$ has prioritized meeting the technical and administrative criteria of the objective review and publication process while maintaining high standards for each submission it receives. The journal's editorial board is committed to a strict adherence of procedure to publish work that represents the academic and intellectual rigor characteristic of internationally-recognized publications.

While the quality of an academic journal is determined by a variety of factors, a primary factor is whether or not it is indexed in internationally recognized databases such as Scopus, Science Citation Index-Expanded (SCIE), and Social Science Citation Index (SSCI) (Huh, 2018). As a journal being listed in such databases serves as a testament to the quality of the academic society that publishes it (Oh, Yeo, \& Park, 2015), countries having a relatively large number of internationally recognized academic journals are considered to hold a strong academic reputation. Governments thus provide institutions with financial support to help them develop their journals with the end of ultimately seeing them listed in international databases.

In 1991, the National Research Foundation (NRF) of Korea initiated a program to help Korean academic journals cover the expenses of the publication process (NRF, 2016; Shin, 2011). 
The aim of this effort was to "strengthen self-sustaining competitiveness, enhance academic variety, promote academic journals of global-level excellence, publish academic journals in Korea, and support the diffusion of diverse research outcomes to promote the activities of academic associations, and improve the quality of academic journals published in Korea" (Kim, Park, \& Ryu, 2016). In 1998, the foundation developed an accreditation system to systematize this program. The evaluation criteria of Korea Citation Index (KCI) accreditation include the number of issues published annually, the timeliness of its publications, the acceptance rate of articles, whether the articles are provided online, the distribution of contributors, the backgrounds of the members of the editorial board, and the rigor of the of article review process. The initial NRF journal accreditation system classified journals into two categories according to their evaluation results: KCI Candidate Journals and KCI Accredited Journals. However, in 2014, the category of KCI Excellent Accredited Journals was introduced to give distinction to journals of an internationally competitive caliber, and the NRF is currently in talks with Elsevier concerning the possibility of including journals in this category in the Scopus database (Lee, 2021).

In 2021, three years after its inaugural issue, BCRP announced that it had applied to receive KCI accreditation. As of July 2021, BCRP is undergoing an evaluation process by the NRF. As $B C R P$ has taken measures to ultimately become an international journal from the very beginning, it is expected to pass the review process without much difficulty. Once it is indexed as a KCI Candidate Journal, BCRP will seek to become a KCI Accredited Journal and ultimately a KCI Excellent Accredited Journal, with the hope of being included in the Scopus database.

$B C R P$ realizing its vision of becoming an internationally recognized academic journal with a distinct voice in the international field of business communication is impossible without the support of the KABC and its partners (Chang \& Kim, 2018). Since $B C R P$ was launched, the $\mathrm{KABC}$ and the people who have supported it have taken on active roles contributing and reviewing articles, publicizing its articles to scholars and practitioners around the world, and networking with potential collaborators. BCRP's designation as a KCI Candidate Journal will be the first fruit of the effort invested by its stakeholders, and it is our hope that this fruit will be the first of many that follow. We appreciate the continued support of the KABC and its partners, and we are excited about the future that awaits us.

\section{References}

Chang, H., \& Kim, J. A. (2018). A step forward for KABC. Business Communication Research and Practice, 1(1), 1-3.

Huh, S. (2018). Recent advances and developments in Korean medical journals: Can a Korean journal paper win the Nobel Prize in physiology or medicine? Journal of the Korean Medical Association, 61(9), 524-531.

Kim, S. H., Park, S. H., \& Ryu, S. H. (2016). Inequality of academic ecosystem through the analysis of researcher-journal network: Case of sociology in Korea. Journal of Social Thoughts and Culture, 19(3), 319-358.

Lee, S. C. (2021). Content analysis of excellent articles registered journal in the National Research Foundataion of Korea: Focused on the social sciences. Korean Journal of Local Government \& Administration Studies, 35(1), 1-17.

National Research Foundation. (2016). Academic journal support project of National Research Foundation. Retrieved from https:// www.nrf.re.kr/biz/info/info/view?biz_no=5

Oh, D., Yeo, Y., \& Park, S. (2015). Analysis of success factors in international journals published by institutions: Focusing on ETRI journal cases. Journal of Information Management, 32(3), 361375.

Shin, E. J. (2011). Activation of publishing domestic SCIE journals based on the situation analysis. Journal of the Korean Society for Library and Information Science, 45(4), 157-178. 